\title{
Fabrication of sensitive fibre-optic gas sensors based on nano-assembled thin films
}

\author{
Sergiy Korposh and Seung-Woo Lee \\ The University of Kitakyushu \\ Japan
}

\section{Introduction}

Optical techniques offer powerful tools for the characterisation of chemical and biological systems. The variety of different designs and measurement schemes of fibre-optic sensors provides the potential to create very sensitive and selective measurement techniques for the purpose of environmental monitoring.

Different approaches exist for creation of fibre-optic sensors (FOS), which generally can be classified into two groups depending on the sensing mechanism: intrinsic and extrinsic fibre-optic sensors (Grattan \& Meggitt, 1999). Intrinsic FOS allows to implement different measurements designs within an optical fibre based on the gratings (Bragg Gratings and long period gratings, LPG ) written into the fibre core in which the changes in the reflected light due to changes in the grating period is measured to detect the effect caused by an external stimulus (Vohra et al., 1999; Schroeder et al., 1999). Interferometric sensors can be made that use some external effect to cause a change in the optical path way or a phase difference in the interferometer caused by some external effect. All traditional interferometers such as Michelson, Mach Zehnder (Bucholtz et al., 1989; Dandridge, 1991; Yuan \& Yang, 2005), Fizeau, Sagnac (Russell \& Dakin, 1999) and Fabry Perot (Rao et al., 2000; Cibu1a \& Donlagic, 2004; Lin et al., 2004) used for measuring of both chemical and physical parameters can be constructed utilizing optical fibres. The other type of intrinsic fibre-optic sensors is based on the evanescent wave absorption effect (Leung et al., 2006).

The advantages of the fibre-optic sensors allow to create measurements systems with the high sensitivity and selectivity, providing an excellent tool for the environmental monitoring. In general, sensitive elements are needed for efficient fibre-optic sensing, which amplify the chemical interaction of analytes and convert it into a measurable optical response as signal. Current research in the field of optical fibre sensors is focusing on the creation and development of new sensitive elements which can expand an application area and increase the number and range of the analytes that can be measured by fibre-optic sensors.

Generally there are some requirements to the sensitive elements of fibre-optic sensors and they should be:

- transparent in the appropriate spectral range;

- change their optical properties under the influence of the specific chemical species; 
- $\quad$ fast in response and have wide dynamic range;

- reversible;

- selective;

- $\quad$ easy to immobilize onto glass/quartz/ plastic fibre;

- $\quad$ easily and cheaply manufactured.

Employing different sensitive elements deposited onto the side of single-mode (MonzónHernández \& Villatoro, 2006) and multimode (Rajan et al., 2005) optical fibres allows the creation of an FOS with high sensitivity and selectivity.

For instance a $\mathrm{pH}$ fibre-optic sensor coated with porous silica film was prepared by the solgel procedure to measure the $\mathrm{pH}$ of the solution with sensors sensitivity up to $0.66 \mathrm{~dB} / \mathrm{pH}$ for the $\mathrm{pH}$ range of 7-10.5 (Rayss \& Sudolski, 2002). Using a sol-gel film doped with a dye (e.g. coumarin, brilliant green, rhodamine 6G, and rhodamine B) (Beltrán-Pérez et al., 2006; Gupta \& Sharma, 1997; Gupta \& Sharma, 1998) the dynamic range of the $\mathrm{pH}$ measurement can be increased to cover $\mathrm{pH}$ values from 2 up to 12 . The sensor sensitivity was increased by decreasing the probe light wavelength, with the highest sensitivity being achieved at $400 \mathrm{~nm}$ (Beltrán-Pérez et al., 2006).

A sensor element doped with polypyrrole was used as a sensitive element for nerve agent detection; using a 1,5 naphthalene disulphonic acid (NDSA) -doped polypyrrole coating produced by the in situ deposition technique a sensitivity of up to $26 \mathrm{ppm}$ with a response time of a few seconds was achieved. Utilizing different deposition techniques and using different doping materials has produced fibre-optic sensors with different sensitivities and performances (Bansal \& El-Sherif, 2005).

The transparency of an optical fibre depends on the fibre material and the wavelength of the probe light. Thus different fibres are appropriate for different spectral ranges; for the near infrared spectra (NIR) the chalcogenide (Lucas et al., 2006; Walsh et al., 1995), for Mid-IR the silver halide (Le Coq et al., 2002; Beyer et al., 2003), and for the UV-Vis quartz (Abdelghani et al., 1997) or plastic optical fibres (Ogita, et al., 2000) can be selected.

Chalcogenide glass fibres were used to perform remote infrared analysis of non-polar organic species in aqueous solution. This technique permits the observation of disruption induced in living mammalian cells by at least two different types of toxins and it is possible to distinguish between the effect of a genotoxic agent (which damages nucleic acids) and a cytotoxic agent (which damages other cellular components) based on the cell's response to IR light (Lucas et al., 2006).

For the detection of chemical species with very low concentration in water, chalcogenide fibres which had special chemical treatment were applied for evanescent wave absorption spectroscopy (Le Coq et al., 2002). The concentration of chloroform and ethanol in water were measured using the variations of their absorbance in the infrared spectral range of 8.6$10 \mu \mathrm{m}$ (Figure 1). The lower limit of detection for ethanol in water was approximately $0.5 \%$, when the length of the sensing zone (removed cladding) was $3 \mathrm{~cm}$ (Le Coq et al., 2002).

A fibre-optic sensor consisting of a silver halide $\left(\mathrm{AgBr}_{x} \mathrm{Cl}_{1-\mathrm{x}}\right)$ optical fibre coated with polyisobutylene (PIB) or Teflon was developed for the in situ monitoring of pesticides and chlorinated hydrocarbons in water for the spectral range of 8.5-12 $\mu \mathrm{m}$ (Beyer et al., 2003). The sensitivity of this FOS was in the region of $100 \mathrm{ppb}$ and it could be enhanced by increasing the interaction of the evanescent field with the investigated medium.

A mid-IR grating spectrometer operating in the wavelength range of $8-12.5 \mu \mathrm{m}$ was developed for the detection of chlorinated hydrocarbons with a detection limit of $900 \mathrm{ppb}$ 
for tetrachloroethylene. The sensor was based on the detection of the characteristic absorption of chlorinated hydrocarbons in the polymer membrane coated onto the sensor silver halide fibre and the effects of the samples on the evanescent field of the guided light (Walsh et al., 1995).

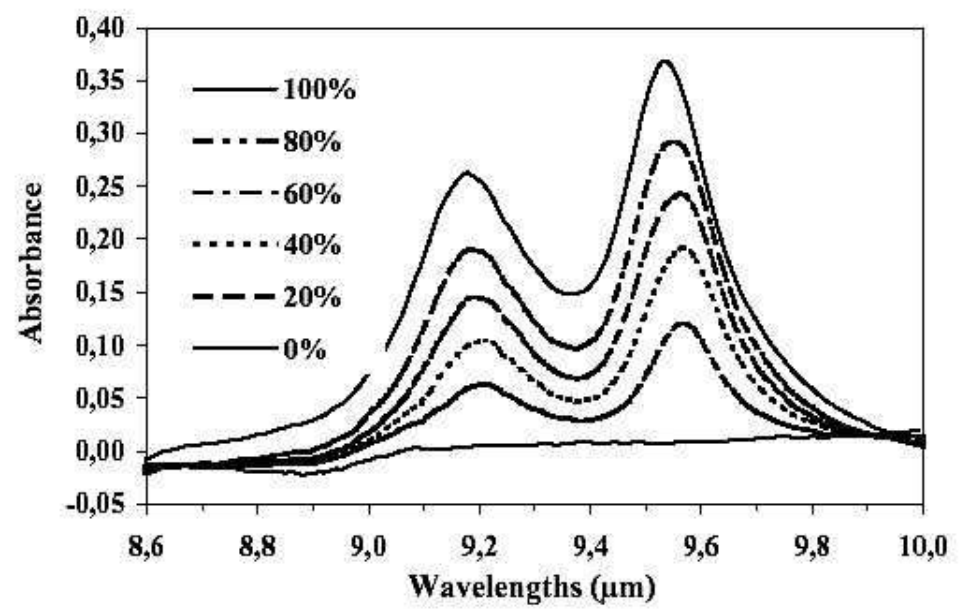

Fig. 1. Absorbance spectrum of the different concentration of ethanol in water measured in the infrared spectral range of 8.6-10 $\mu \mathrm{m}$ (Le Coq et al., 2002)

The most suitable fibres in the visual spectral range for the creation of intrinsic FOS based on the generation of an evanescent wave are the plastic cladded silica fibres (PCS); because the plastic cladding can be easily removed by mechanical stripping or by means of chemical etching. This FOS coated with an appropriate sensitive material could be used for the detection of chemical parameters and species (Kawahara et al., 1983; Sharma \& Gupta, 2005; Ronot et al., 1994).

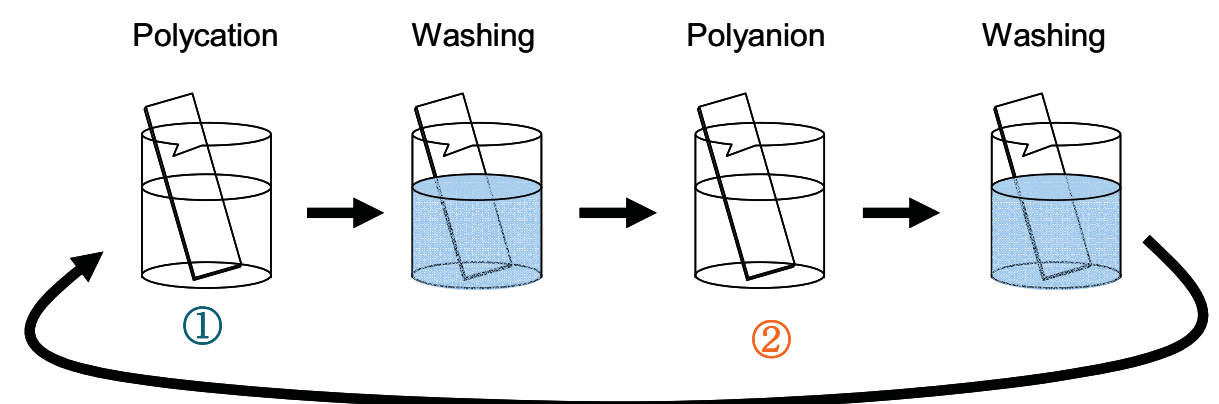

Fig. 2. Schematic illustration of the layer-by-layer (LbL) method

In the deposition of a sensitive coating onto the optical fibre it is crucial to provide the sensor with stable parameters and prevent the functional material from leaching or desorbing from the optical fibre. Different immobilization procedures based on the covalent 
and noncovalent bond could be used for the deposition of the sensitive element onto the optical fibre. The Langmuir-Blodgett (LB) technique has been employed for the coating of the fibre-optic with aim of devloping long period grating fibre sensor (James \& Tatam, 2006). This deposition technique allows to control material at nanolevel and is based on the transferring of the orientated monolayers onto the solid substrate. Alternative approach is the electrostatic layer-by-layer (LbL) method that has been useful for the preparation of molecularly assembled films with the good adhesion properties to the quartz surfaces, Figure 1 (Iler, 1966; Ichinose et al., 1996). One of the advantageous of this method over LB process is that wide class of materials can be deposited on the different types of surfaces. This deposition technique is still expanding its potential because of its versatility for fabrication of ordered multilayers with well controlled thickness and the possibility to use both inorganic and organic materials (Lee et al., 1998).

Porphyrin compounds can be used as a sensitive element for optical sensors because their optical properties (absorbance and fluorescence features) depends on the environmental conditions in which molecule is present (Takagi et al., 2006). Porphyrins are tetrapyrrolic pigments that widely occur in nature and play an important role in many biological systems (Kadish et al., 2000). The optical spectrum of the solid state porphyrin is modified as compared to that of porphyrin in solution, due to the presence of strong $\pi-\pi$ interactions (Schick et al., 1989). Interactions with other chemical species can produce further optical spectral changes, thus creating the possibility that they can be applied to optical sensor systems. The high extinction coefficient $\left(>200,000 \mathrm{~cm}^{-1} / \mathrm{M}\right)$ makes porphyrin especially attractive for the creation of optical sensors.

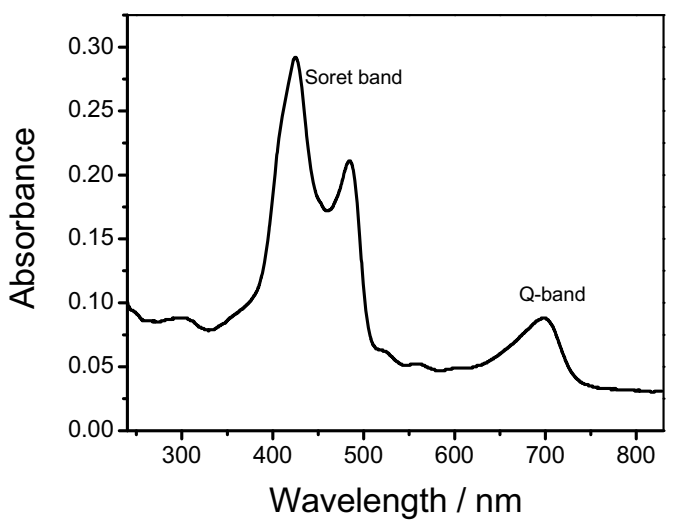

Fig. 3. Absorbance spectrum of a J-aggregated porphyrin film deposited onto a quartz substrate (Korposh et al., 2006)

For example, Fig. 3 shows a typical absorbance spectrum of tetrakis-(4sulfophenyl)porphine (TSPP) in an alternate film with a cationic polymer, which consists of two Soret bands (425 and $484 \mathrm{~nm}$ ) and one pronounced Q-band (700 nm). Exposure of the porphyrin compound to chemical analytes leads to the alternation of the J-aggregation 
which in turn changes the absorbance spectrum and this phenomenon can be used for the optical sensor development (Korposh et al., 2006).

Moreover, the optical properties of the porphyrin compound can be controlled by metallation of its core which in turn will lead to a higher sensitivity and wider class of chemical compounds that could be measured, Fig. 4 (Rakow \& Suslik, 2000). Exposure of a metalloporphyrin sensor array to chemical species leads to the different colour change which can be used for the fibre-optic sensor development.

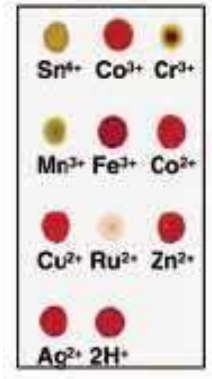

TPP array

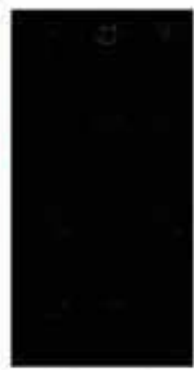

Control $5 \operatorname{min~} \mathrm{N}_{2}$

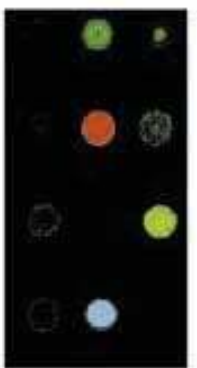

$30 \mathrm{sec}$

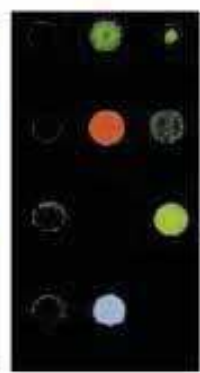

$5 \mathrm{~min}$

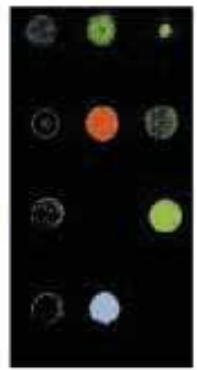

$15 \min$

Fig. 4. Colour change profiles of a metalloporphyrin sensor array as a function of exposure time to $n$-butylamine vapour (Rakow \& Suslik, 2000)

In this chapter, we would like to describe the use of the LbL method for the deposition of a porphyrin thin film onto a multimode silica core/plastic clad optical fibre with the aim of developing an evanescent wave fibre optic gas sensor. A short section of the plastic cladding was replaced with a functional coating of alternate poly(diallyldimethylammonium chloride) (PDDA) and TSPP layers. The measurement principle of the device is based on the ammonia-induced optical change in the transmission spectrum of the coated optical fibre. As light travels along the core of the optical fibre, a small portion of energy penetrates the cladding in the form of an evanescent wave, the intensity of which decays exponentially with the distance from the interface between the cladding and the surrounding environment. The penetration depth $\left(d_{p}\right)$ of the evanescent wave is described by (Grattan \& Meggitt, 1999):

$$
d_{p}=\frac{\lambda}{2 \pi\left(n_{e f f}^{2}-n_{c}{ }^{2}\right)^{1 / 2}},
$$

where $\lambda$ is the wavelength of light in free space, $n_{c}$ is the refractive index of the cladding and $n_{\text {eff }}$ is the effective refractive index of the mode guided by the optical fibre. The deposition of a functional coating layer onto the optical fibre leads to the chemically induced modulation in the transmission spectrum and provides quantitative and qualitative information on the chemical species under examination. The employment of the proposed fibre optic sensor based on the intrinsic evanescent wave has an additional advantage to offer cheap and compact devices, due to combination of light emitting diode (LED) and photodetector components. Moreover, the sensitivity of the device can be improved by varying the length of the sensing area and the process for film deposition will be less timeconsuming. 


\section{Evanescent wave fibre-optic sensor}

\subsection{Sensor fabrication}

Tetrakis-(4-sulfophenyl)porphine (TSPP) and poly(diallyldimethylammonium chloride) (PDDA, Mw: 200000-350000, $20 \mathrm{wt} \%$ in $\mathrm{H}_{2} \mathrm{O}$ ) were purchased from Tokyo Kasei, Japan (Fifure 2). Deionized pure water $(18.3 \mathrm{M} \Omega \cdot \mathrm{cm})$ was obtained by reverse osmosis followed by ion exchange and filtration (Nanopure Diamond, Barnstead, Japan). An HCS200 multimode silica core/plastic cladding optical fibre (OF) with core and cladding diameters of $200 \mu \mathrm{m}$ and $400 \mu \mathrm{m}$, respectively, was purchased from Ocean Optics (USA). Standard ammonia gas of 100 ppm in dry air was purchased in a cylinder from Japan Air Gases Corp. All of these chemicals were of analytical grade and used without further purification.
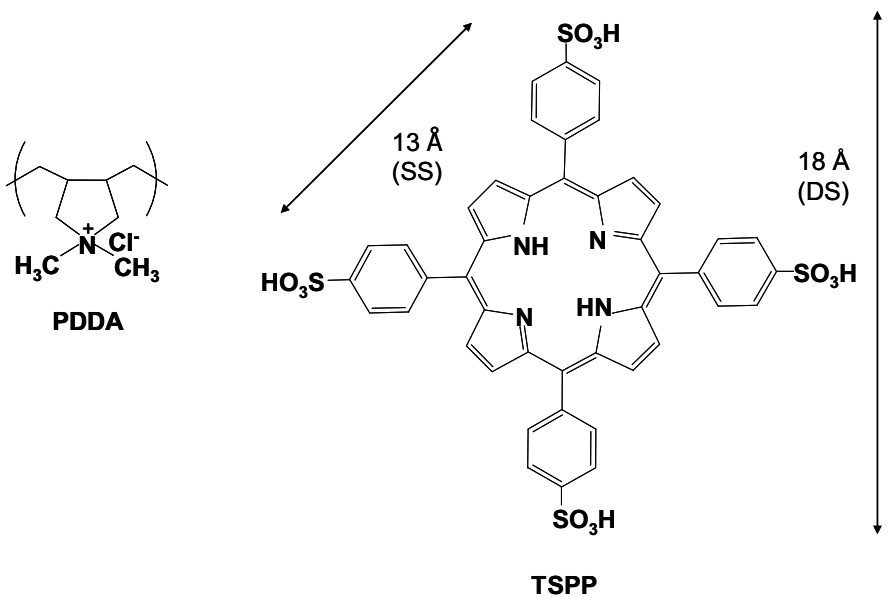

Fig. 5. Structural models of the polycation (PDDA) and porphyrin (TSPP) compounds used in this study (Agira et al., 1997): SS, side length of square; DS, diagonal length of square

The electrostatic layer-by-layer adsorption method was employed for the deposition of a porphyrin thin film onto a multimode optical fibre (OF). A schematic illustration of this method using PDDA and TSPP is shown in Fig. 6a. A multimode optical fibre from which the plastic cladding has been removed over an area $1 \mathrm{~cm}$ in length was rinsed in ethanol and distilled water prior to film deposition. The plastic cladding could be easily burned off from the fibre using a burner flame (temperature $<500{ }^{\circ} \mathrm{C}$, the property of the silica core is not changed within the temperature range.). One end of the optical fibre was connected to a deuterium-halogen light source (DH-2000-Ball, Mikropack), the other end was connected to a spectrometer (S1024DW, Ocean Optics). The stripped section of the optical fibre was fixed within a special deposition cell for film preparation, as shown in Fig. 6b.

Before assembly, the previously stripped section of the optical fibre was cleaned with concentrated sulfuric acid $(96 \%)$, rinsed several times with deionized water, and treated with $1 \mathrm{wt} \%$ ethanolic $\mathrm{KOH}$ (ethanol/water $=3: 2, \mathrm{v} / \mathrm{v}$ ) for about $10 \mathrm{~min}$ with sonication in order to functionalize the surface of the silica core with a $\mathrm{OH}$ group. The fibre core was then rinsed with deionized water, and dried by flushing with dry nitrogen gas. The film is denoted $\left(\mathrm{PDDA}^{+} / \mathrm{TSPP}-\right)_{\mathrm{x}}$, where $\mathrm{x}=5$ and indicates the number of adsorption cycles. The 
film was prepared by the alternate deposition of PDDA ( $5 \mathrm{mg} \mathrm{mL}^{-1}$ in water) and TSPP (1 $\mathrm{mM}$ in water) (where one cycle is considered to be a combined PDDA ${ }^{+} / \mathrm{TSPP}$ - bilayer) by introducing a coating solution $(150 \mu \mathrm{L})$ into the deposition cell with intermediate processes of water washing and drying by flushing with nitrogen gas being undertaken between the application of layers. In every case, the outermost surface of the alternate film was TSPP.

(a)

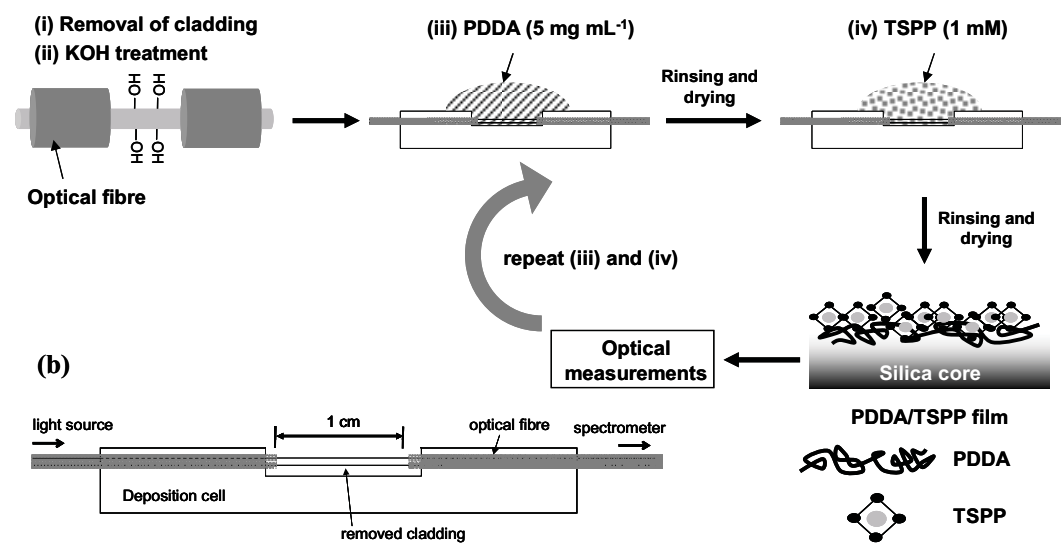

Fig. 6. (a) Schematic illustration of the layer-by-layer adsorption of TSPP and PDDA on a multimode optical fibre and (b) deposition cell used for coating the optical fibre

The assembly process was monitored using an S1024DW spectrometer (Ocean Optics). The absorbance was determined by taking the logarithm of the ratio of the transmission spectrum of the coated fibre, $\mathrm{T}(\lambda)$, to the transmission spectrum measured prior to film deposition $T_{0}(\lambda)$,

$$
A(\lambda)=-\log \frac{T(\lambda)}{T_{0}(\lambda)}
$$

The assembly process was characterised and the thickness of the film was measured using a quartz crystal microbalance technique, as described in our previous work (Korposh et al., 2006).

\subsection{Optical measurements}

The desired gas concentrations were produced using a two-arm flow system, as shown in Fig. 7a. Dry compressed air and ammonia gas of $100 \mathrm{ppm}$ passed through two flowmeters, and the two flows were recombined with a final analyte concentration (volume fraction) $c$ in the measurement chamber being calculated using,

$$
c=\frac{L_{1} \cdot z}{L_{1}(1+z)+L_{2}}
$$

where $z$ is the mole fraction of ammonia, and $L_{1}$ and $L_{2}$ are the flow rates of dry air and ammonia gas, respectively. $L$ (where $L=L_{1}+L_{2}$ ) was kept constant at $1 \mathrm{~L} \mathrm{~min}^{-1}$ and ammonia concentration was adjusted by varying $L_{1}$ and $L_{2}$. A specially designed sensor 
chamber made of Teflon (Fig. 7b) was used in order to estimate the ammonia response. The optical fibre coated with the functional film was inserted inside the chamber and connected to the light source and spectrometer, as shown in Fig. $7 \mathrm{~b}$.

(a)

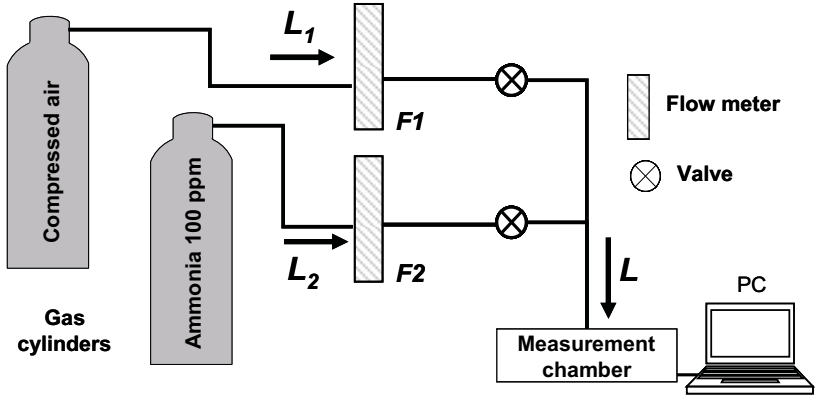

(b)

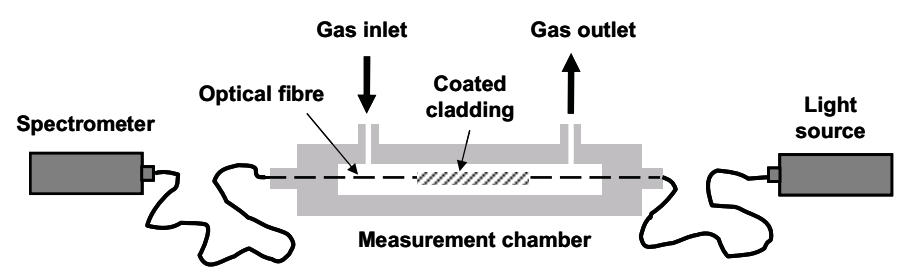

Fig. 7. (a) Apparatus of a two-arm flow gas generation system: F1 and F2 are flowmeters; $L_{\mathrm{i}}$ represents the concentration of the gases in the different arms of the system. (b) Schematic illustration of the measurement setup: light source, Ocean optics light source emitting light in the range of wavelengths from 200 to $1100 \mathrm{~nm}$; spectrometer, Ocean Optics S1024DW spectrometer

The sensor response at a given analyte concentration was measured every second by recording the transmission spectrum of the film deposited on the optical fibre. The difference spectrum was plotted by subtracting a spectrum measured at a given analyte concentration from the spectrum recorded in the presence of dry air. The baseline spectrum of each experiment was recorded by passing dry air through the measurement chamber until the signal measured at wavelengths of 350, 470 and $706 \mathrm{~nm}$ reached equilibrium. The dynamic sensor response was also measured at the same wavelengths.

The optical fibre sensor response (SR) was calculated using

$$
\mathrm{SR}=100\left(I_{0}-I\right) / I_{0},
$$

where $I_{0}$ and $I$ describe the light intensities of the PDDA ${ }^{+} /$TSPP- film in the absence and presence of the analyte gas, respectively, measured at a given wavelength. 


\section{Results and Discussion}

\subsection{Optical spectra of PDDA ${ }^{+} / \mathrm{TSPP}^{-}$alternate layers}

The assembly of the PDDA and TSPP layers after each deposition cycle was measured by monitoring the optical change in the transmission spectra of the optical fibre. Fig. 8 shows the evolution of the transmission spectrum of the optical fibre during the deposition of a five-cycle PDDA+/TSPP- thin film.

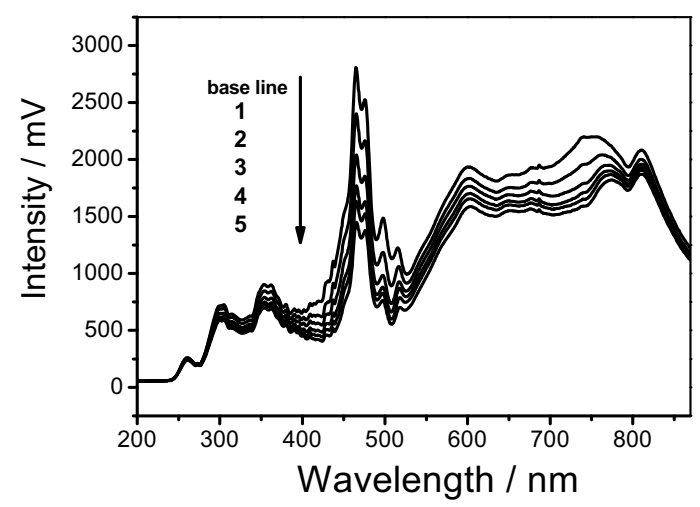

Fig. 8. Evolution of the transmission spectra (data as measured) as a multilayer film of $\mathrm{PDDA}^{+}$/TSPP- that was deposited onto a $200 \mu \mathrm{m}$ core diameter multimode optical fibre with a stripped silica core of $1 \mathrm{~cm}$

The absorbance spectra were derived from the transmission spectra using eq. (2), Figure 9a. The largest absorbance due to the deposition of the (PDDA $\left.{ }^{+} / \mathrm{TSPP}-\right)$ bilayer was observed at a wavelength of $420 \mathrm{~nm}$, which corresponds to the Soret band. The absorbance increased in proportion to the number of adsorption cycles (Fig. 9a). The absorbance spectra of the (PDDA ${ }^{+}$/TSPP-) film are characterized by a double peak in the Soret band occurring at 420 and $480 \mathrm{~nm}$, and by a pronounced peak of the $\mathrm{Q}$ band at $706 \mathrm{~nm}$. These spectral characteristics suggest that TSPP molecules exist in the J-aggregate state, in which the absorbance maxima of the Soret and $\mathrm{Q}$ bands are red-shifted compared with those in the monomeric state (Agira et al., 1997; Gregory van Patten et al., 2000; Snitka et al., 2005). The aggregation state of TSPP and hence its spectral features are controlled by the protonation/deprotonation of the porphyrin pyrrole ring (Agira et al., 1997). Fig. 9b shows the absorbance change monitored at two Soret bands $(420$ and $480 \mathrm{~nm})$ and at the $Q$ band (706 $\mathrm{nm})$ versus the number of adsorption cycles. 
(a)

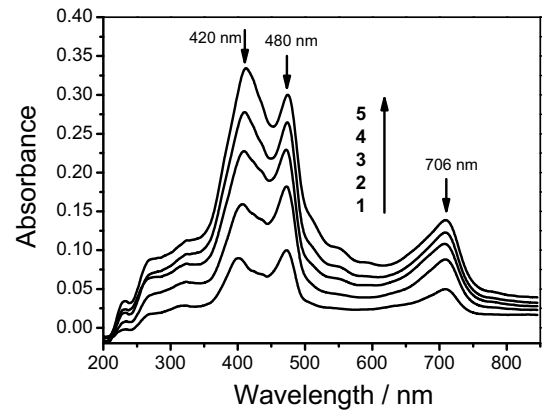

(b)

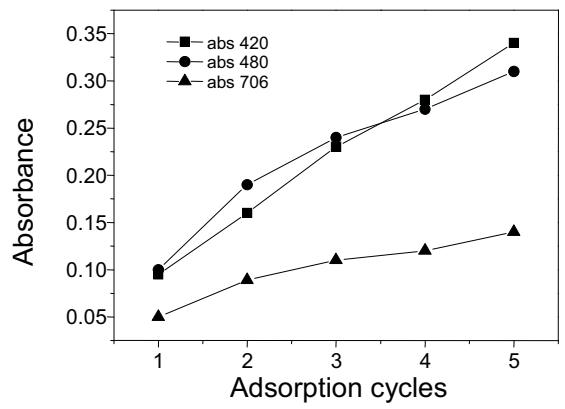

Fig. 9. Evolution of the spectrum as a multilayer film of PDDA+/TSPP- that was deposited onto a $200 \mu \mathrm{m}$ core diameter multimode optical fibre with a stripped silica core of $1 \mathrm{~cm}$ : (a) absorbance spectra (derived from the transmission spectra using eq. (2); (b) absorbance change due to film deposition monitored at wavelengths of $420 \mathrm{~nm}$ (squares), $480 \mathrm{~nm}$ (circles), and $706 \mathrm{~nm}$ (triangles).

\subsection{Optical response to ammonia}

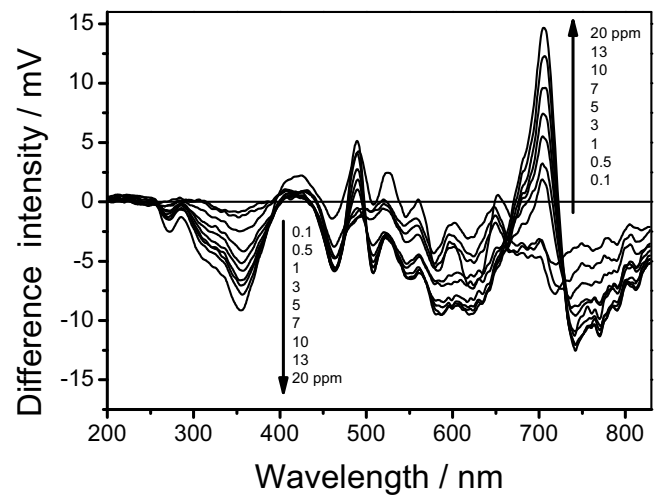

Fig. 10. Optical transmission difference spectra of the optical fibre consisting of a five-cycle $\mathrm{PDDA}^{+} / \mathrm{TSPP}-$ alternate film for ammonia concentrations ranging from 0-20 ppm.

Ammonia-induced optical changes in the transmission spectrum of the (PDDA ${ }^{+}$TSPP- $)_{5}$ film are shown in Fig. 10. As ammonia concentration increased from 0 to $20 \mathrm{ppm}$, the intensity change occurs at several wavelengths; at $706 \mathrm{~nm}$, intensity increases, whereas at 350 and $470 \mathrm{~nm}$ it decreases. Upon exposure of the (PDDA $\left.{ }^{+} / \mathrm{TSPP}-\right)_{5}$ film to ammonia, the largest intensity change was observed at $706 \mathrm{~nm}$. The interaction between ammonia and TSPP molecules leads to the deprotonation from the pyrolle ring and hence affects the interaction between TSPP molecules. Similarly, the largest change in absorbance is observed 
at $706 \mathrm{~nm}(\mathrm{Q}$ band), which is attributed to the aggregation structure of TSPP (Gregory van Patten et al., 2000).

(a)

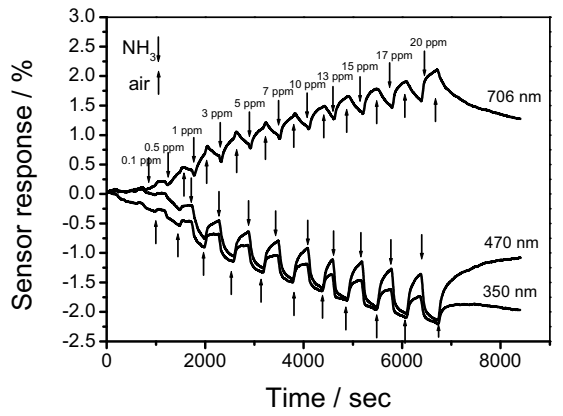

(b)

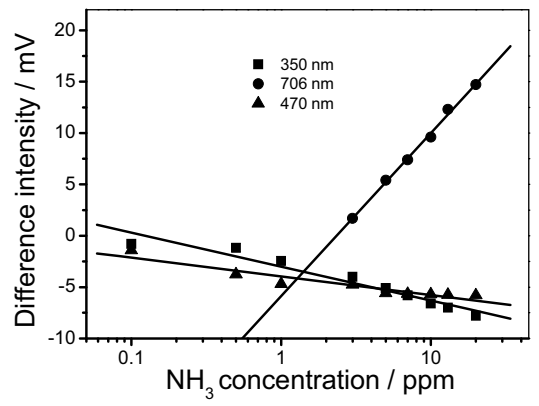

Fig. 11. (a) Dynamic response of the optical fibre consisting of a five-cycle PDDA $^{+} / \mathrm{TSPP}^{-}$ alternate film for ammonia concentrations ranging from 0-20 ppm at 350, 470, and $706 \mathrm{~nm}$. (b) Calibration curves at $350 \mathrm{~nm}$ (squares), $470 \mathrm{~nm}$ (rhombuses), and $706 \mathrm{~nm}$ (circles). Lines show the linear fitting and are used only as guidance to an eye.

The dynamic sensor response of the ( $\left.\mathrm{PDDA}^{+} / \mathrm{TSPP}^{-}\right)_{5}$ film to ammonia was monitored at 350, 470 and $706 \mathrm{~nm}$ (Fig. 11a). As can be seen from the result, the sensor response is fully reversible for low ammonia concentrations (up to $1 \mathrm{ppm}$ ). However, at higher concentrations the recovery time of the sensor response takes a longer time to return to the base line. The base line may be recovered when flushed with air for sufficient time, as shown in Fig. 11a. Alternatively, the sensor response can be regenerated by rinsing for a few seconds in distilled water (Korposh et al., 2006). The calibration curve at each wavelength was plotted from the recorded spectra at given ammonia concentrations. The sensor shows linear responses at all wavelengths for a wide concentration range from 0.1 to $20 \mathrm{ppm}$ and the highest sensitivity was observed at $706 \mathrm{~nm}$ (Fig. 11b).

Table 1 shows a summary of the sensor parameters, including sensitivity, response and recovery times and limit of detection $(L O D)$ measured at different wavelengths. The response and recovery times $\left(t_{90}\right)$ of the sensor to increasing ammonia concentration were within 1.6-2.5 min and 1.8-3.2 min, respectively (see Fig 11a). The sensitivity of the sensor depends on the wavelength and has different directions; for 350 and $470 \mathrm{~nm}$, it is negative, and for $706 \mathrm{~nm}$ it is positive. The highest sensitivity was measured at $706 \mathrm{~nm}$, corresponding to the optical change of the Q band of TSPP.

The current sensor system has a limit of detection $(L O D)$ on the ppm order ranging from 0.9 to $2.6 \mathrm{ppm}$. The limit of detection was defined according to $L O D=3 \sigma / m$, where $\sigma \approx 0.31$ is the standard deviation, and $m$ is the slope $(\Delta I / \Delta c)$ of the calibration curve, where $c$ is the ammonia concentration and $I$ is the measured intensity $(\mathrm{mV})$ (Swartz \& Krull, 1997). The presence of different features in the optical spectrum after exposing the PDDA $^{+} / \mathrm{TSPP}^{-}$film to ammonia offers the ability to create a low-cost fibre optic sensor by selecting a LED and a photodiode with parameters that will coincide with the wavelength at which the largest ammonia-induced changes were observed $(706 \mathrm{~nm})$. Difference spectra derived from Fig. 8 
were obtained by subtracting a spectrum measured in ammonia atmosphere from a spectrum measured in air.

\begin{tabular}{|c|c|c|c|c|c|}
\hline $\begin{array}{c}\text { wavelength } \\
\text { / nm }\end{array}$ & $\begin{array}{c}\text { a Sensitivity } \\
\text { / slope }\end{array}$ & $\begin{array}{c}\mathrm{b} \text { Response time } \\
/ \mathrm{min}\end{array}$ & $\begin{array}{c}\mathrm{b} \text { Recovery time } \\
/ \mathrm{min}\end{array}$ & $\begin{array}{c}\text { Linear range } \\
/ \mathrm{ppm}\end{array}$ & $\begin{array}{c}\mathrm{c} L O D \\
/ \mathrm{ppm}\end{array}$ \\
\hline 350 & $-0.50 \pm 0.08$ & 2.0 & 1.8 & $0.1-20$ & 1.90 \\
\hline 470 & $-0.35 \pm 0.06$ & 2.5 & 2.4 & $0.1-20$ & 2.65 \\
\hline 706 & $0.98 \pm 0.07$ & 1.6 & 3.2 & $0.1-20$ & 0.90 \\
\hline
\end{tabular}

a Slope calculated from the calibration curve (Fig. 11b).

b Response and recovery times determined as the interval needed for the signal to achieve $90 \%$ of their saturated condition when measured of an $\mathrm{NH}_{3}$ concentration of 10 ppm.

c LOD: limit of detection.

Table 1 . Summary of the sensors parameters (sensitivity, response and recovery times, and limit of detection) for the five-cycle $\mathrm{PDDA}^{+} / \mathrm{TSPP}-$ film.

\subsection{Sensing mechanism}

Porphyrin compounds can be used as sensitive elements for optical sensors because their optical properties (absorbance and fluorescence features) depend on the environmental conditions in which chemicals are present (Takagi et al., 2006). Generally, the change of porphyrin absorption spectra is induced by (i) solvent effects, (ii) redox reactions, (iii) the protonation or metallation of core nitrogen atoms, (iv) п-п electron interaction, (v) electronic changes due to structural changes such as flattening or distortion, or (vi) interactions between porphyrins (aggregation) (Takagi et al., 2006). The alternation of the spectral features observed when the $\left(\mathrm{PDDA}^{+} / \mathrm{TSPP}-\right)_{5}$ film was exposed to ammonia (Fig. 10 suggests the following mechanisms of the interaction between TSPP and ammonia gas:

(i) Interaction between ammonia and porphyrin compounds leads to the deprotonation of the TSPP pyrolle ring and the formation of ammonium ions, as shown in Fig. 12. This deprotonation leads to the disruption of J-aggregation and is mainly accompanied by spectral changes occurring at 470 and 706 nm (Agira et al., 1997; Gregory van Patten et al., 2000; Takagi et al., 2006);

(ii) We can speculate that a decrease in the transmittance noted at $350 \mathrm{~nm}$ may be attributed to the distortion of the aggregation structure due to the adsorption of ammonia (Takagi et al., 2006);

The above mentioned sensing mechanisms are mainly based on the dissociation of $J$ aggregated TSPP molecules and the original structure of the $\mathrm{PDDA}^{+} / \mathrm{TSPP}-$ film can be recovered by protonation from ammonium ions. The future challenge is to test the selectivity of the proposed device. Preliminary results obtained by exposing the fibre optic sensor coated with the five-cycle PDDA+/TSPP- film to some of volatile organic compounds (VOCs) revealed a higher selectivity towards amine compounds (data not shown). 

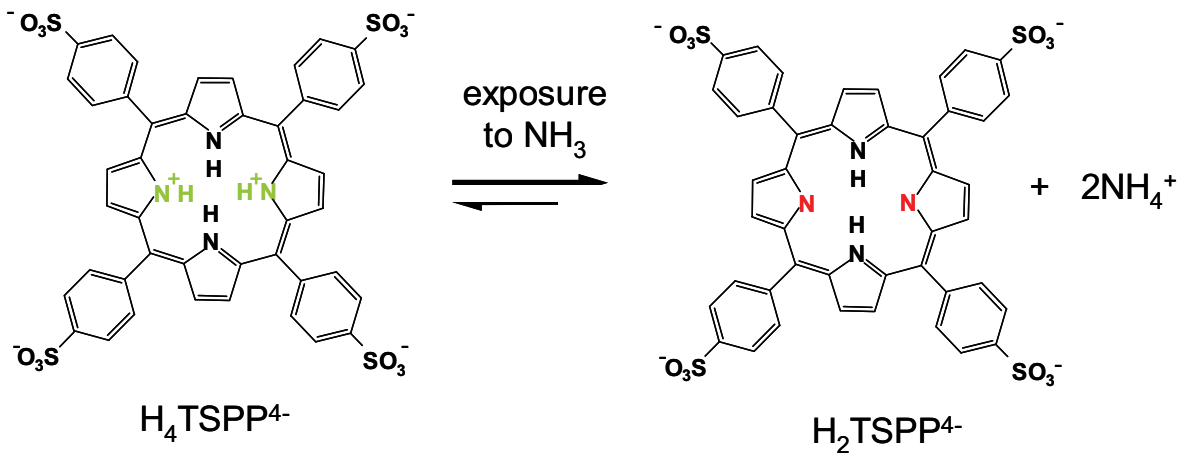

Fig. 12. Schematic representation of the interaction between ammonia and TSPP compounds in the $\mathrm{PDDA}^{+}$/TSPP- film.

\section{Conclusion}

In conclusions, fibre optic sensors combined with the chemically reactive element provide a wide range of possibilities for the development of the cheap, sensitive and highly selective sensor systems. As an example, a fibre optic ammonia sensor based on a $\mathrm{PDDA}^{+} / \mathrm{TSPP}^{-}$ alternate thin film deposited on the core of a multimode optical fibre using a layer-by-layer approach is demonstrated. The intensity of the light propagating through the optical fibre decreases proportionally with the increase in the thickness of the TSPP layers deposited over the optical fibre. The exposure of the five-cycle PDDA+/TSPP- film to ammonia induces changes in the absorption spectrum via the deprotonation of TSPP, which could be observed in the transmission spectrum of the coated optical fibre. The highest sensitivity $(0.98 \mathrm{mV}$ $\mathrm{ppm}^{-1}$ ) was observed when measured at $706 \mathrm{~nm}$, which corresponds to the $\mathrm{Q}$ band of the porphyrin compound; for low-cost-sensor development it is possible to use a simple LEDphotodiode system operating at around $700 \mathrm{~nm}$. The sensor showed a linear sensitivity to the presence of ammonia with a limit of detection of $0.9 \mathrm{ppm}$ in the concentration range of 0.1-20 ppm and sensor response and recovery times were less than $4 \mathrm{~min}$. The demonstrated sensor offers an opportunity for the detection of different chemicals by coating an optical fibre with an appropriate sensitive material. Further work is needed to optimize sensor performance and to study the effect of coating thickness, relative humidity and presence of the other chemical compounds on sensor parameters.

\section{References}

Abdelghani, A.; Chovelon, J. M.; Jaffrezic-Renault, N.; Lacroix, M.; Gagnaire, H.; Veillas, C.; Berkova, B.; Chomat, M. \& Matejec, V. (1997). Optical fibre sensor coated with porous silica layers for gas and chemical vapour detection. Sensors and Actuators B: Chemical, Vol. 44, No. 1-3, p. 495-498, ISSN 0925-4005

Ariga, K.; Lvov, Y. \& Kunitake, T. (1997). Assembling alternate dye-polyion molecular films by electrostatic layer-by-layer adsorption. Journal of American Chemical Society, Vol. 119, No. 9, p. 2224-2231, ISSN 0002-7863

Bansal, L. \& El-Sherif, M. (2005). Intrinsic optical-fibre sensor for nerve agent sensing. IEEE Sensors Journal, Vol. 5, No. 4, p. 648-655, ISSN 1530-437X 
Beltrán-Pérez, G.; López-Huerta, F.; Muñoz-Aguirre, S.; Castillo-Mixcóatl, J.; PalominoMerino, R.; Lozada-Morales, R. \& Portillo-Moreno, O. (2006). Fabrication and characterization of an optical fibre $\mathrm{pH}$ sensor using sol-gel deposited $\mathrm{TiO}_{2}$ film doped with organic dyes. Sensors and Actuators B: Chemical, Vol. 120, No. 1, p. 74-78, ISSN 0925-4005

Beyer, T.; Hahn, P.; Hartwig, S.; Konz, W.; Scharring, S.; Katzir, A.; Steiner, H.; Jakusch, M.; Kraft, M. \& Mizaikoff, B. (2003). Mini spectrometer with silver halide sensor fibre for in situ detection of chlorinated hydrocarbons. Sensors and Actuators B: Chemical, Vol. 90, No. 1-3, p. 319-323, ISSN 0925-4005

Bucholtz, F.; Dagenais, D. M. \& Koo, K. P. (1989). High frequency fibre-optic magnetometer with $70 \mathrm{fT}$ per square root hertz resolution. Electronics Letters, Vol. 25, No. 25, p. 1719-1721, ISSN 0013-5194

Cibu1a, E. \& Donlagic, D. (2004). All-fibre Fabry-Perot strain sensor. Proceedings of 2nd European Workshop on OFS, pp. 180-183, ISBN 9780819454348, Spain, June 2004, SPIE

Dandridge, A. (1991). Fibre optic sensors based on the Mach-Zehnder and Michelson interferometers, In: Fiber Optic Sensors: An Introduction for Engineers and Scientists, edited by E. Udd. New York: Wiley

Grattan, K.T.V. \& Meggitt, B.T. (1999). Chemical and environmental sensing, Dordrecht, Boston : Kluwer

Gregory van Patten, P.; Shreve, A.P. \& Donohoe, R.J. (2000). Structural and photophysical properties of a water-soluble porphyrin associated with polycations in solutions and electrostatically-assembled ultrathin films. Journal of Physical Chemistry:B, Vol. 104, No. 25, p. 5986-5992, ISSN 1089-5647

Gupta, B. D. \& Sharma, D. K. (1997). Evanescent wave absorption based fibre optic pH sensor prepared by dye doped sol-gel immobilization technique. Optical Communications, Vol. 140, No. 1-3, p. 32-35, ISSN 0030-4018

Gupta, B. D. \& Sharma, S. (1998). A long-range fibre optic pH sensor prepared by dye doped sol-gel immobilization technique. Optical Communications, Vol. 154, No. 5-6, p. 282284, ISSN 0030-4018

Ichinose, I.; Fujiyoshi, K.; Mizuki, S.; Lvov, Yu. \& Kunitake, T. (1996). Layer-by-layer assembly of aqueous bilayer membranes on charged surfaces. Chemical Letters, Vol. 25, No. 4, p. 257-258, ISSN 1348-0715

Iler, R. K. (1966). Multilayers of Colloidal Particles. Journal of Colloid Interface Science, Vol. 21, No. 6, p. 569-594, ISSN 0021-9797

James, S. W. \& Tatam R. P. (2006). Fibre optic sensors with nano-structured coatings. Journal of Optics A: Pure and Applied Optics, Vol. 8, No. 7, p. S430-S444, ISSN 1741-3567

Kadish, K. M.; Smith, K. M. \& Guilard R. (2000). The Porphyrin Handbook, Academic Press, ISBN 0123932009, San-Diego

Kawahara, F. K.; Fuitem, R. A.; Silvus, H. S.; Newman, F. M. \& Frazar, J. H. (1983). Development of a novel method for monitoring oils in water. Analytical Chimia Acta, Vol. 151, p. 315-327, ISSN 0003-2670

Korposh, S. O.; Takahara, N.; Ramsden, J. J.; Lee, S-W. \& Kunitake, T. (2006). Nanoassembled thin film gas sensors. I. Ammonia detection by a porphyrin-based multilayer film. Journal of Biological and Physical Chemistry, Vol. 6, No. 3, p. 125-133, ISSN 1512-0856 
Le Coq, D.; Michel, K.; Keirss, J.; Boussard- Plédel, C.; Fonteneau, G.; Bureau, B.; Le Quéré, J.-M.; Sire, O. \& Lucas, J. (2002). Infrared glass fibres for in-situ sensing, chemical and biochemical reactions. Comptes Rendus Chimie, Vol. 5, No. 12, p. 907-913, ISSN 1631 0748

Lee, S.-W.; Ichinose, I. \& Kunitake, T. (1998). Molecular Imprinting of Azobenzene Carboxylic Acid on a TiO2 Ultrathin Film by the Surface Sol-Gel Process. Langmuir, Vol. 14, No. 10, p. 2857-2863 ISSN 0743-7463

Leung, A.; Rijal, K.; Shankar, P. M. \& Mutharasan, R. (2006). Effects of geometry on transmission and sensing potential of tapered fibre sensors. Biosensors and Bioelectronics, Vol. 21, No. 12, p. 2202-2209, ISSN 0956-5663

Lin, C.-J.; Tseng, Y.-T.; Lin, S.-C.; Yang, C.-S. \& Tseng, F.-G. (2004). A novel in-vitro and insitu immunoassay biosensor based on fibre-optic Fabry-Perot interferometry, Proceedings of 2nd European Workshop on Optical Fibre Sensors, pp. 304-307, ISBN 9780819454348, Spain, June 2004, SPIE

Lucas, P.; Solis, M. A.; Le Coq, D.; Juncker, C.; Riley, M. R.; Collier, J.; Boesewetter, D. E.; Boussard-Plédel, C. \& Bureau, B. (2006). Infrared biosensors using hydrophobic chalcogenide fibres sensitized with live cells. Sensors and Actuators B: Chemical, Vol. 119 , No. 2, p. 355-362, ISSN 0925-4005

Monzón-Hernández, D. \& Villatoro, J. (2006). High-resolution refractive index sensing by means of a multiple-peak surface plasmon resonance optical fibre sensor. Sensors and Actuators B: Chemical, Vol. 115, No. 1, p. 227-231, ISSN 0925-4005

Ogita, M.; Nagai, Y.; Mehta, M. A. \& Fujinami, T. (2000). Application of the adsorption effect of optical fibres for the determination of critical micelle concentration. Sensors and Actuators B: Chemical, Vol. 64, No. 1-3, p. 147-151, ISSN 0925-4005

Rajan; Chand, S. \& Gupta, B. D. (2005). Fabrication and characterization of a surface plasmon resonance based fibre-optic sensor for bittering component-Naringin. Sensors and Actuators B: Chemical, Vol. 115, No. 1, p. 344-348, ISSN 0925-4005

Rakow, N.A. \& Suslick, K. S. (2000). A colorimetric sensor array for odour visualization. Letters to Nature, Vol. 406, 710-713, ISSN 0028-0836

Rao, Y. J.; Cooper, M. R.; Jackson, D. A.; Pannell, C. N. and Reekie, L. (2000). High resolution static strain measurement using an in-fibre-Bragg-grating-based Fabry Perot sensor. Proceedings of 14th International Conference on Optical Fibre Sensors, pp. 284-287, October 2000, Italy, SPIE

Rayss, J. \& Sudolski, G. (2002). Ion adsorption in the porous sol-gel silica layer in the fibre optic pH sensor. Sensors and Actuators B: Chemical, Vol. 87, No. 3, p. 397-405, ISSN 0925-4005

Ronot, C.; Gagnalre, H.; Goure, J. P.; Jaffrezic-Renault, N. \& Plchery, T. (1994). Optimization and performance of a specifically coated intrinsic optical-fibre sensor for the detection of alkane compounds. Sensors and Actuators B: Chemical, Vol. 42, No. 1-3, p. 529-534

Russell, S. J. \& Dakin, J. P. (1999). Location of time-varying strain disturbances over a $40 \mathrm{~km}$ fibre section, using a dual-Sagnac interferometer with a single source and detector. Proceedings of $13^{\text {th }}$ International Conference on Optical Fibre Sensors, pp. 580-584, ISBN 9780819432285, Korea, April 1999, SPIE 
Schick, G.A.; Schreiman, I.C.; Wagner, R.W.; Lindsey, J.S. \& Bocian, D.F. (1989). Spectroscopic characterization of porphyrin monolayer assemblies. Journal of American Chemical Society, Vol. 111, No. 4, p. 1344-1350, ISSN 1520-5126

Schroeder, R. J.; Yamate, T. \& Udd, E. (1999). High pressure and temperature sensing for the oil industry using fiber Bragg gratings written onto side hole single mode fiber. Proceedings of $13^{\text {th }}$ International Conference on Optical Fibre Sensors, pp. 42-45, ISBN 9780819432285, Korea, April 1999, SPIE

Sharma, A. K. \& Gupta, B. D. (2005). Fibre optic sensor based on surface plasmon resonance with nanoparticle films. Photonics and Nanostructures - Fundamentals and Applications, Vol. 3, No. 1, p. 30-37, ISSN 1569-4410

Snitka, V.; Rackaitis, M. \& Rodaite, R. (2005). Assemblies of TPPS 4 porphyrin investigated by TEM, SPM and UV-vis spectroscopy. Sensors and Actuators B: Chemical, Vol. 109, No. 1, p. 159-166, ISSN 0925-4005

Swartz, M. E. \& Krull, I. S. (1997). Analytical Method Development and Validation, Marcel Dekker, Inc. NY, USA

Takagi, S.; Eguchi, M.; Tryk, D. A. \& Inoue, H. (2006). Porphyrin photochemistry in inorganic/organic hybrid materials: Clays, layered semiconductors, nanotubes, and mesoporous materials, J. Photochem. Photob. C: Photochem. Rev., Vol. 7, No. 2-3, p. 104126, ISSN 1389-5567

Vohra, S. T.; Todd, M. D.; Johnson, G. A.; Chang, C. C. \& Danver, B. A. (1999). Fibre Bragg grating sensor system for civil structure monitoring: applications and field tests, Proceedings of $13^{\text {th }}$ International Conference on Optical Fibre Sensors, pp. 32-37, ISBN 9780819432285, Korea, April 1999, SPIE

Walsh, J. E.; MacCraith, B. D.; Meaney, M.; Vos, J. G.; Regan, F.; Lancia, A. \& Artioushenko, S. (1995). Midinfrared fiber sensor for the in-situ detection of chlorinated hydrocarbons. Proceedings of Chemical, Biochemical, and Environmental Fiber Sensors VII, pp. 233-237, ISBN: 9780819418661, Munich, June 1995, SPIE

Yuan, L., \& Yang, J. (2005). Two-loop based low-coherence multiplexing fibre optic sensors network with Michelson optical path demodulator, Proceedings of 17th International Conference on Optical Fibre Sensors, pp. 595-598, ISBN 9780819458551, Bruges, May 2005, SPIE 


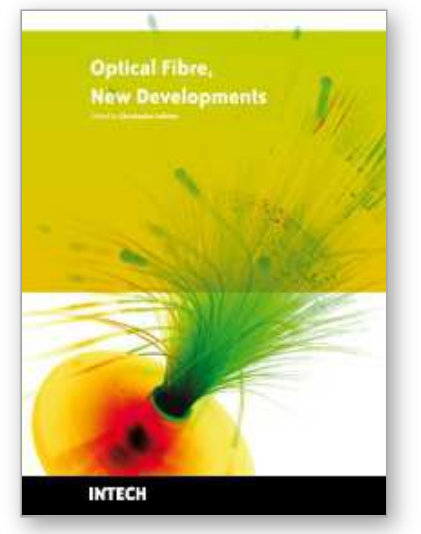

\section{Optical Fiber New Developments}

Edited by Christophe Lethien

ISBN 978-953-7619-50-3

Hard cover, 586 pages

Publisher InTech

Published online 01, December, 2009

Published in print edition December, 2009

The optical fibre technology is one of the hop topics developed in the beginning of the 21th century and could substantially benefit applications dealing with lighting, sensing and communication systems. Many improvements have been made in the past years to reduce the fibre attenuation and to improve the fibre performance. Nowadays, new applications have been developed over the scientific community and this book fits this paradigm. It summarizes the current status of know-how in optical fibre applications and represents a further source of information dealing with two main topics: the development of fibre optics sensors, and the application of optical fibre for telecommunication systems.

\section{How to reference}

In order to correctly reference this scholarly work, feel free to copy and paste the following:

Sergiy Korposh and Seung-Woo Lee (2009). Fabrication of Sensitive Fibre-Optic Gas Sensors Based on Nano-Assembled Thin Films, Optical Fiber New Developments, Christophe Lethien (Ed.), ISBN: 978-9537619-50-3, InTech, Available from: http://www.intechopen.com/books/optical-fiber-newdevelopments/fabrication-of-sensitive-fibre-optic-gas-sensors-based-on-nano-assembled-thin-films

\section{INTECH}

open science | open minds

\section{InTech Europe}

University Campus STeP Ri

Slavka Krautzeka 83/A

51000 Rijeka, Croatia

Phone: +385 (51) 770447

Fax: +385 (51) 686166

www.intechopen.com

\section{InTech China}

Unit 405, Office Block, Hotel Equatorial Shanghai

No.65, Yan An Road (West), Shanghai, 200040, China

中国上海市延安西路65号上海国际贵都大饭店办公楼 405 单元

Phone: +86-21-62489820

Fax: $+86-21-62489821$ 
(C) 2009 The Author(s). Licensee IntechOpen. This chapter is distributed under the terms of the Creative Commons Attribution-NonCommercial-ShareAlike-3.0 License, which permits use, distribution and reproduction for non-commercial purposes, provided the original is properly cited and derivative works building on this content are distributed under the same license. 